\title{
Healthcare Information Giving Services: Technologies and Everyday Practicalities
}

Link to publication record in Manchester Research Explorer

\section{Citation for published version (APA):}

Clarke, K., Procter, R., Rooksby, J., Rouncefield, M., \& Slack, R. (2004). Healthcare Information Giving Services:

Technologies and Everyday Practicalities. In Proceedings of the Healthcare and Digital Libraries Workshop

\section{Published in:}

Proceedings of the Healthcare and Digital Libraries Workshop

\section{Citing this paper}

Please note that where the full-text provided on Manchester Research Explorer is the Author Accepted Manuscript or Proof version this may differ from the final Published version. If citing, it is advised that you check and use the publisher's definitive version.

\section{General rights}

Copyright and moral rights for the publications made accessible in the Research Explorer are retained by the authors and/or other copyright owners and it is a condition of accessing publications that users recognise and abide by the legal requirements associated with these rights.

\section{Takedown policy}

If you believe that this document breaches copyright please refer to the University of Manchester's Takedown Procedures [http://man.ac.uk/04Y6Bo] or contact uml.scholarlycommunications@manchester.ac.uk providing relevant details, so we can investigate your claim.

\section{OPEN ACCESS}




\section{Healthcare Information Giving Services: Technologies and Everyday Practicalities}

\author{
Karen Clarke, John Rooksby, Mark \\ Rouncefield \\ Computing, University of Lancaster \\ Lancaster LA1 4YW, UK \\ +44 (0)1524593490 \\ $\{k . c l a r k e$, m.rouncefield, \\ j.rooksby\}@lancaster.ac.uk
}

\author{
Rob Procter, Roger Slack \\ Social Informatics Cluster, School of \\ Informatics, University of Edinburgh, \\ Edinburgh EH8 9LW, UK \\ +44 (0)131650 4412
}

\{rnp, rslack\}@inf.ed.ac.uk

\begin{abstract}
This paper presents findings from observational studies of work practice in two 'information giving' services: Scottish Poisons Information Bureau and The Mental Health Helpline as a precursor to informing the design of such services. Our work highlights the interactions that constitute the requesting and giving of information and the role of intermediaries in the delivery of recipient-designed information. We propose a shift of focus from the logic of information in system design to one that encompasses the practicalities of information giving.
\end{abstract}

Keywords: Information giving services; intermediaries

\section{INFORMATION GIVING SERVICES AND THE NHS}

Recent policy shifts in healthcare in the UK have argued for an increased role for IT as the route to a more effective healthcare service. The 'beautiful logic' [5] is one where IT is seen as key to the solution of the 'healthcare problem' and in this way it is argued that healthcare will become more effective, timely and dependable. Such arguments tend to obscure the nature healthcare professionals' work in favour of reengineering it.

We present some early findings from observational studies of work practice in a number of 'information giving' settings. The initial intention is to discover how current information resources, both paper- and computer-based, are actually used as a precursor to system design and evaluation. Our interest is in the embedded nature of such resources, and how this informs our understanding of the information and communication needs of healthcare professionals, voluntary workers and patients in information giving services.

The emphasis is on understanding the everyday, practical accomplishment of 'information giving' work in the NHS, particularly as it relates to the use of IT by healthcare professionals and voluntary staff. The objective of our research is to uncover, through an ethnographic study the nature, value and possible future development of the IT systems currently being utilised. IT-based information giving services utilise systematised corpuses of knowledge: the ethnographic explication of 'common sense' and work practice of members who use the corpus may provide 'useful' information for designing or improving the corpuses. The main emphasis is on evaluating systems in use as the necessary precursor to an iterative process of system re-design. As Bannon [1] notes: "Given that our designs will inevitably be flawed, the important point is that the results of these designs are tested and the findings used to help in the re-design process. Indeed, in recent years, this realisation of the inevitable need for re-design has become a commonplace."

While acknowledging the difficulties involved in any evaluation - in particular, determining 'users'; defining measures of 'utility' and so on - we believe that ethnographic accounts can be useful in helping to inform the requirements process, through developing an appreciation of the 'application domain' that is, how people work with or around designed systems [7]: "a careful systematic account of what happens in particular settings when a prototype or system is installed, and how the system is viewed by the people on the ground, can provide useful information for "evaluating" the system and its fitness for the purpose it was designed" [1].

\section{THE CASE STUDIES}

\subsection{Scottish Poisons Information Bureau}

Unlike, for example, North America [4], advice on the management of accidental or deliberate ingestion of toxic substances or overdoses of substances is not given to members of the public: in the UK such inquiries are managed through healthcare professionals. For example, a patient may present at their general practitioner's office or the local hospital emergency room; parents, relatives, carers and so forth may telephone NHSDirect/24 to inquire about substance ingestion: in all these cases, advice on management will be given either to or through a healthcare professional. Poisons advice for healthcare professionals in the UK is delivered in the following ways: 
- TOXBASE, a web-based database of poisons data that contains information on substances, their toxicity and management strategies for healthcare professionals treating patients.

- A network of poisons information centres located throughout the UK to which phone calls can be made if further information is required or if information cannot be found on TOXBASE.

We focus here on the work of Information Officers (IOs) in the Scottish Poisons Information Bureau (SPIB). The results we report are drawn from six months observation of activities at SPIB and a corpus $(\sim 100)$ of tape recorded calls.

A primary concern is information use and information management across professional boundaries with specific reference to the use of IT within these services. How is information oriented to by healthcare professionals? By this we mean both advisors and those seeking advice. We argue that advising and being advised are thoroughgoingly social in character and that what we see is not simply the reading of information to a healthcare professional who thereby understands what must be done. Our focus is on the notion of 'doing advising' - we use the term 'doing' as we attend to the situated practices of advising (on the part of both IOs and callers) in terms of the uses of information by IOs and in terms of speech exchanges between IOs and callers. That is to say, attending to 'doing advising' highlights advice as an achievement, an artful accomplishment co-operatively undertaken in real time.

\subsection{The Mental Health Helpline}

A series of observational studies was conducted at an organisation called The Mental Health Helpline. The results reported here are drawn observations of 12 four-hour shifts made over a period of six months.

The Helpline was launched in 1996 by an NHS Trust after the need for an out of hours information and listening service was identified in a major review of local Mental Health Services. The helpline was set up for use by 'mental health survivors', users, carers and relatives and is staffed by volunteers. These come from all walks of life and have 12 weeks of training before they are able to operate the line. The Helpline is confidential except in cases where there is a perceived threat to life (such as a suicide call) and provides a freephone number. The helpline aims to empower callers with a choice about how their own healthcare is provided.

The Helpline holds details of statutory and voluntary services on its database, and also holds a large quantity of literature that can be forwarded to users on request. This large body of information must continually be updated. The helpline also logs call information that is used to provide detailed reports of needs for mental health service provision and for helpline services. The Helpline has been successful and whilst increasing the geographic areas that it covers has recently had to use technology to block calls from beyond this area. The
Helpline is seeking to make much of its information available online.

The Helpline has many regular callers and rarely receives direct requests for information. There is no clear distinction between a listening call and an information call, in that callers wanting to talk might benefit from information they did not know or had not considered, and those who are calling for information rarely know what it is they need. Operating the Helpline can be a gruelling task, callers often being difficult to talk to and often having harrowing stories. In the near future the Helpline foresees expansion to providing information not just for service users but also providers. Service providers such as GPs will increasingly have to give their patients choices about services. The Helpline's information will be useful for this purpose and provision of information online is part of this strategy.

\section{FIELDWORK EVIDENCE}

Here we present examples of information giving from our fieldwork. They show how information giving is a real time, collaborative accomplishment on the part of both the information services and callers.

\subsection{SPIB}

"“Calls" are best described as ongoing and developing sequences of action, actions that get formed up into organizational events' [11].

In a previous paper [8], we noted that there are broadly three openings in queries to SPIB:

- "Is there anything I should be concerned about in a patient who has taken (substance)?"

- "Our TOXBASE is down: can you give me some information on (substance)?"

- 'I can't find any information on (substance) in TOXBASE - can you help?"

Information officers will give the required information in all of the above types of call. In the main, the information officer will read from the TOXBASE entry, but $\mathrm{s}$ /he can also draw upon other sources. In the data extracts that follow we show how information giving works, concentrating on:

- Formulating reason for calling

- Doing searching

\subsubsection{Formulating reason for calling}

Extract One (Note: The following transcripts use conversation analytic notation. For a summary of these conventions, see [10]).

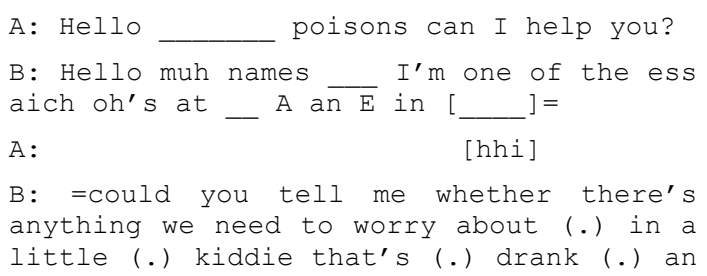


unknown quantity of compact disc cleaning fluid=

A: =right hhh ok

(....)

A: how old's your patient?

B: errrm its a toddler (.) I've just had a phone call from a (.) worried mum

\section{Extract Two}

A: hello poisons can I help you?

B: hello yes, it's sister here at I wonder if you could give me a wee bit of advice I've got a fifteen month old baby he's fine he's well he's no frothing at the mouth he's no vomiting nothing.

\section{Extract Three}

A: poisons information bureau=

B: =Hello, I just wonder (.) my names' one of the GPs at? it's just

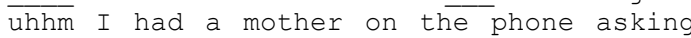
about a two and a half year old that had taken probably errm or maximum three aspirin but probably one or two aspirin three hundred milligram and that was twenty four hours ago and the child's been absolutely fine since (.)

A: $\mathrm{mmhmm}=$

B: = I'd just wondering whether we should do anything about it

We see that in the first case the caller formulates their reason for calling, asking "if there is anything we need to worry about" as well as giving their source of information; in the second, the caller asks for advice and gives a candidate set of symptoms; and in the third case, again we see both the basis for information, maximum dose and candidate description of symptoms. Information requests have within them an orientation to what the IO might be expected to need to know. Indeed, the caller's opening utterances might be thought of as 'recipient designed' [9] to give information and to exhibit the call worthiness of the call: that is, they set out the information required for IO to provide an appropriate response and to secure the call as a poisons call. Apropos of Whalen's comment above, we can see that this initial formulation is a necessary predicate for the organizational event of doing poisons advising.

\subsubsection{Doing Searching}

In many cases the information that callers require information about is relatively easy to obtain using TOXBASE. However, given the large number of household cleaners and so forth currently available it is not always possible to find information on a specific brand directly from TOXBASE. In these cases, the information officers will use a number of other information resources. In the following extract (a continuation of extract one, above) the IO is given the generic substance 'compact disc cleaning fluid': IO seeks further information:

(Extract One Cont'd)

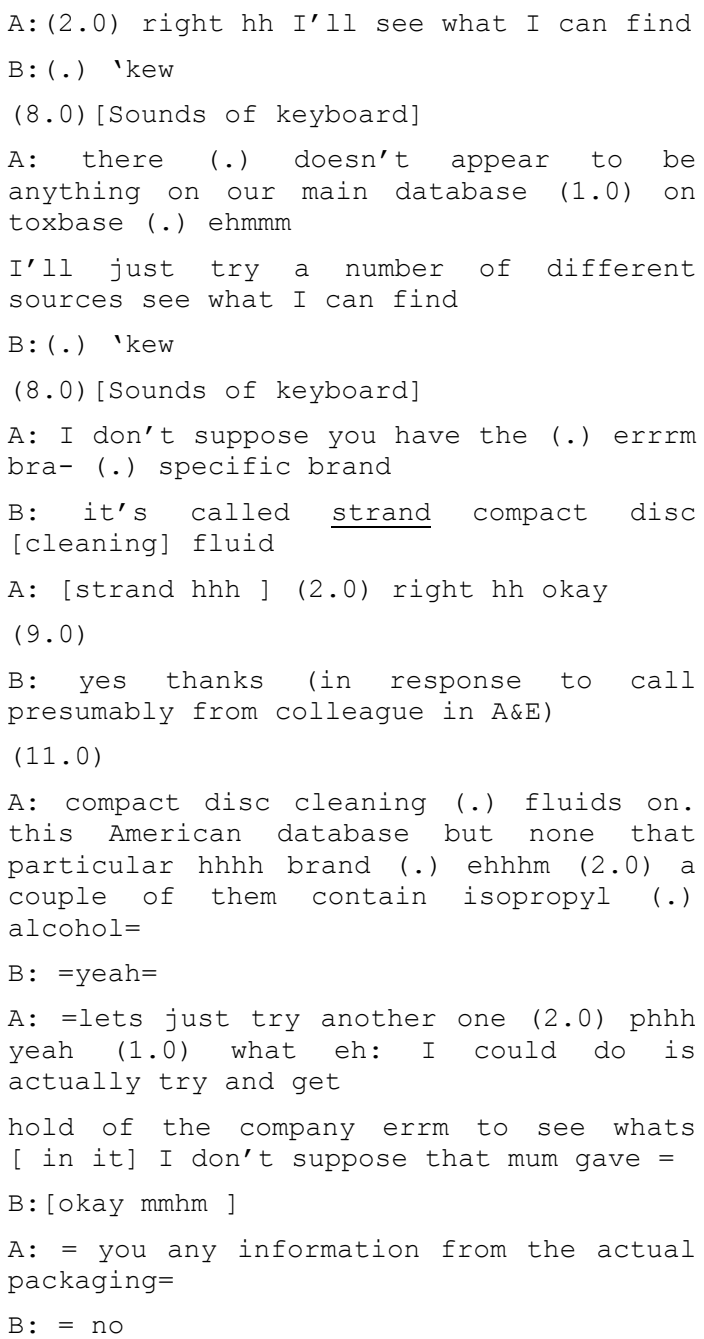

In the above we see how IO gathers information from the caller and how IO fits information and a narrative of their ongoing search into the interaction. That IO cannot find information on the substance is instructive for our purposes in that it shows IOs knowledge work over a range of potential resources (in this case webbased, but in other calls paper-based resources such as $\mathrm{BNF}$ are used) as the call continues. IO skilfully consults a wide range of information while maintaining an interaction with the caller. In another context this has been called improvisational choreography [13], i.e., the 'available to hand' arrangement of information resources so as to be able to respond to callers without interruptions and so on. Further, we should not imagine that calls are in any way routine - any sense of routine is an achievement of the IO. IO orients both to callers' displayed knowledge and information in a range of databases in order to fulfil the request. The transcript shows how IO shapes the call to organisational-informational requirements during its course. At the outset caller does not specify age or gender of the child and does not give information about symptoms or time of ingestion (all of which are central to giving correct advice): IO repairs these gaps in vivo. 
Looking at what IO says during the call regarding the presence of isopropyl alcohol in the CD cleaner, we see another feature of advising, candidate formulations. These are made across our corpus where a product such as toilet cleaner can be said to have a set of generic ingredients: they are not a definitive statement of contents but a 'placeholder' so as to alert callers to potentially problematic substances (often callers respond, saying that substances mentioned were what they had thought may be present). This strategy of flagging candidate substances fits with callers' questions as to what 'we need to worry about': that is to say, both parties orient to what are immediate concerns as a part of the course of advice giving. The candidate status of these formulations should be kept in mind. From prior experience IOs can offer a formulation of what a product may contain, they do not definitively state that substances are present. In all cases IOs produce a full account of the constituent substances and relevant treatment strategies.

What Watson [11] calls 'doing the organisation's work' requires that both IOs and callers enter into a collaborative 'practical sense making' enterprise when transacting information. It is not mere reading out and transparent understanding: information transaction is an achievement of both parties. Callers formulate their reason for call and their case details as well as their understanding of the information given by IOs and IOs perform a range of intermediary roles that fit with the displayed needs of the caller regarding the substance ingested and its management. IOs suggest candidate accounts, and repair both misunderstandings and the adequacy of information given (as well as suggesting potential sources for acquiring more information).

\subsection{The Mental Helpline}

The Helpline provides a 'listening and information service'. The majority of calls are classified as listening, whereby the operator will have a conversation with someone experiencing mental health problems or caring for someone experiencing these problems. Information may be given or offered as a part of these calls. Information calls are less frequent: operators might receive about one or two in a four hour shift. Information calls where the caller is simply asking a question are rare; the only clear-cut examples are students or service providers wishing to find out about specific issues or services in the region. Most information calls involve a combination of listening and information giving, where the operator works to discover and classify problems and then to find information relevant to those problems.

The following example is from part of a call lasting fifty one minutes made by a woman whose baby has been taken into care. Due to issues of confidentiality, only the operator's utterances were recorded: caller's turns at talk are indicated using three periods. The call begins with the operator establishing that this is a new caller:

hello...is this the first time you've rung? and continues with establishing how the caller might be helped

Can you give me some more information about what we might do to help you?

There is now a two or minute conversation about the woman's baby being taken into care, during which time the operator also tries to establish information about the woman's circumstances:

how old was the baby? ... are your other children with you? ... do you see them? ... are you living on your own? ... how often do you see your health visitor? ... have you got any friends? Why did you move to [this area]? ... do you visit the baby regularly?

At this point the operator starts to look up information, not about care, but about self-harm. The conversation continues:

do you see your doctor? ...Its hard when you get involved with social services ... What kind of benefits are you on? ... It's income support isn't it. You really need someone to advise you with this.

The operator then asserts

I've got information on self harm. I've just brought the information up on my screen.

The operator then reads the caller some information about a national support organisation for women who self injure, including the telephone number. The operator then says

I was wondering if there is anything in [your] area.

She then silently reads some details about the National Self Harm Network

I'm just reading something off the screen... no ... this is [City].

The operator then goes to the filing cabinets and removes the self harm folder. She leafs through

Hello... I've got a leaflet on Understanding Self Harm. Now, we could send that to you.

The operator continues to leaf through, she pulls out a leaflet Advice for Friends and Family, puts it back and continues to leaf through. She does this with another leaflet, while asking

What's happening with the baby at the moment? ... They haven't said they'll put her up for adoption yet?

The operator takes out a leaflet 'Minimising the Damage from Self Harm' and puts it by the phone. The operator continues talking

Have you told them that he's violent? ... You were in a hostel? ... A refuge.

and then establishes

Is that how you found the telephone number of this? 
The conversation continues, the operator is now not looking through the leaflets or at the computer

And you don't know people ... You say you have mental health problems? ... depression ... Do you think you've a lack of support?

The operator then starts going through the A-Z menu on the computer

I'm just wondering if Advocacy can help you at all. ... You could ring numbers ..

are you on the phone in your flat? ... do you have a phone? ... I'm just wondering if Advocacy. I don't know. I've just brought up advocacy on screen ... It could be that the C.A.B. could, you know ... this is not just to do with mental health.

The operator then starts going through other advocacy organisations on the computer

That's not the one, that's for homeless ... I'm just looking through ... I'll go back. This is the C.A.B. in [nearby city].

Have you actually been in touch with them? ... they have an awful lot of information."

When this call ends the operator comments "The caller has got all the support she needs. She is embroiled in it all, social services etc. ... She is probably trying to let off some steam." She adds "you only get to hear their side of the story". This comment is made after a long a difficult conversation with a distressed woman with mental health difficulties. The operator has acted as an intermediary in this call by both listening to and questioning the caller and attempting to categorise problems so that relevant information or organisations can be found. The operator has also provided a service simply by allowing the caller to talk through her difficulties and let off some steam.

\section{GETTING A 'BEAUTIFUL LOGIC' TO WORK: CONFIGURATION, ADEQUACY OF RESPONSES AND USABILITY}

While undoubtedly 'evaluation' has taken on some of the characteristics of an advertiser's 'weasel word', few contest its importance. However, the evaluation of IT systems is especially difficult, not least because of uncertainties over what exactly constitutes an evaluation, how it should be implemented and when and where it should take place. Grudin [6], for example, cites the difficulty of evaluation as just one contributory factor in why $\mathrm{CSCW}$ systems fail to deliver the benefits intended. In particular, the view that evaluation should be regarded principally as a summative process is deeply problematised by any interest in the 'real world' context of use. Thus Bannon [1] argues that design, use and evaluation should not be viewed as distinct activities, but as being necessarily interwoven and that 'evaluation' issues, informed by the context of use, should effectively saturate the design process.
In this preliminary ethnographic evaluation we recognise the complex and particular needs of organisational users and providers of information giving services. Configuration is both a design issue and a system user issue. The systems involved in these settings need to incorporate a degree of flexibility and responsiveness e.g., in the light of changes to prescribed drugs, availability of voluntary services, particular toxic hazards etc. Information resources such as TOXBASE have a range of users and use scenarios, were designed originally with healthcare professionals in mind but now have much wider public access. The structure of TOXBASE is navigable by those who are familiar with it, but occasional users need guidance and interpretation of its contents. Of particular interest here are the design issues involved in the scripting of appropriate responses to particular types of service user, responses that may also incorporate security and privacy issues. In a similar fashion, the Mental Health Helpline was designed with service users in mind, but now faces expansion to provide information to service providers. Set up as an out-of-hours phone service, it now faces providing an all hours, online service. These two groups have similar and related information needs, but access and request it in very different ways.

Our studies of SPIB and the Mental Health Helpline have sought to understand the context of searching and interpretation of systematised corpuses of knowledge. They illustrate the sometimes invaluable contribution of the intermediary in navigating and making sense of a range of both paper- and computer-based information resources. They also indicate that we should reflect on other ways in which information giving services may be supported:

- Tailoring of information organisation to local needs.

- Evolving information organisation around patterns of use (cf [13]).

- Sharing searching strategies and outcomes: making these accountable to the callers as shown in the CD cleaner inquiry to SPIB and the reading of information on self harm in the Mental Health Helpline.

In the case of the Mental Health Helpline, the emphasis is similarly on an intermediary with expertise in translating between everyday talk and the provisions of the database - with the operator mediating between medical language and the everyday world through a range of interrogative devices.

The extracts presented here have a design relevance. As Bowker and Star [3] note, "tools need to be sensitive to the working conditions of those encoding the data." (p159) and "Imposed standards will produce work-arounds. Because imposed standards cannot account for every local contingency, users will tailor standardized forms, information systems, schedules and so forth to fit their needs." (idem). A part of the work of advising is the development of practical classification schemes. We find that while in some 
cases information is pre-structured (in terms of database entries and so on), other information has to be made to come to hand as it were. That is to say, there is a mutually elaborative relationship between classification schemes and the work in which they are embedded, based in part on prior experience of doing advising. In terms of design, then, we need to look to these practical 'ontologies' in order to be able to design work affording artefacts. The 'beautiful logics' to which advocates of 'informated' [14] procedures subscribe can sit uneasily with the practical business of doing everyday work. 'Beautiful logics' are persuasive but ignore practical work (usually by reengineering it). We advocate the use of ethnography by designers to explore work practice since, without it, it is likely that the beauty of logics will rapidly be seen to be skin deep.

To conclude, key research questions that arise in both settings and with both technologies are whether the database can be presented in a more effective manner so that access to key information is not overlooked by end users; whether the needs of the various types of users are adequately met within the format of the database; and whether standard statements used in the database convey the appropriate clinical action categories intended by the authors. In the case of the Mental Health Helpline, given that operators have a variety of backgrounds and approaches to callers, should the user interface support a variety of methods or support one 'best practice'? To what extent should intermediary expertise be write-able into the database - e.g., by highlighting or grouping? Given expertise is neither uniform nor universal, consideration should be given to the impacts of such interventions and the potential for their being shared within an organisation. Put simply, what one person regards as useful/logical may be counterintuitive to a colleague (and may be a barrier to their work). Allied to this we should also examine the impact of user interfaces on expertise and interaction: what are the affordances of interfaces? Do they assist or obstruct the work of advice giving?

Factors which influence the potential success of new technology concern matters of design: in particular, unless issues such as ergonomics, interface design, ease of use, and fit with daily work routines are addressed at the outset then new IT initiatives court failure. Indeed, there may be a significant tension between the demands of day-to-day activities centred around patient care and the requirements of orderly information management and audit. This tension and how it is managed represents an important dynamic in the ongoing construction and refinement of information systems.

\section{REFERENCES}

1. Bannon, L. (1996). Use, Design and Evaluation: Steps towards an Integration. In: D. Shapiro, M. J. Tauber, and R. Traunmuller, eds. The Design of Computer Supported Cooperative Work and Groupware Systems. Amsterdam. Elsevier. pp. 423-444.
2. Berg, M. (1997). Rationalising Medical Work: Decision Support techniques and Medical Practices. Cambridge: MIT Press.

3. Bowker, G. \& Star, S. L. (1999). Sorting Things Out: Classification and Its Consequences. Cambridge MA: MIT Press.

4. Frankel, R.M. (1989). "I wz wonderinguhm could Raid uhm effect the Brain permanently d'y know?" Western Journal of Speech Communication 53: 195-226.

5. Gregory, J. (2000). The Sorcerer's Apprentice. Unpublished PhD Dissertation, Department of Communication, University of California, San Diego.

6. Grudin, J. (1988). Why CSCW Applications Fail: Problems in the Design and Evaluation of Organizational Interfaces. In Proceedings of ACM CSCW'88 Conference on ComputerSupported Cooperative Work, ACM press.

7. Heath, C. and Luff, P. (1996). Documents and Professional Practice: 'bad' organizational reasons for 'good' clinical records. In Proceedings of CSCW'96, Boston.

8. Procter, R., Slack, R. S. and Bateman, D. N. (2003). Information, intermediaries and interaction in medical work. Keynote presentation at HDL 2003, Trondheim.

9. Sacks, H. and Schegloff, E.A. (1979). Two preferences in the organization of reference to persons in conversation and their interaction. In G. Psathas, ed., Everyday language: studies in ethnomethodology. New York: Irvington. pp. 152.

10. Schenkein, J. N. (1978). Explanation of Transcript Notation. In: J.N Schenkein, ed. Studies in the organization of conversational interaction. New York: Academic Press pp. xvxvi

11. Watson, D.R. (1986). Doing the organizations work: an examination of a crisis intervention centre. In: S. Fisher and A. D. Todd, eds. Discourse and institutional authority. Norwood, N.J.: Ablex. pp. 911-20.

12. Whalen, J. (1995). A technology of order production: Computer-aided dispatch in public safety communication. In: P. ten Have and G. Psathas, eds. Situated order: Studies in the social organization of talk and embodied activities. Washington, D.C.: University Press of America: 187-230.

13. Whalen, J., Whalen, M. and Henderson, K. (2002). Improvisational choreography in teleservice work. British Journal of Sociology 53(2), pp. 239-258.

14. Zuboff, S. (1988). In the Age of the Smart Machine. New York: Basic Books. 